This is the author's final, peer-reviewed manuscript as accepted for publication. The publisher-formatted version may be available through the publisher's web site or your institution's library.

\title{
Rotary ultrasonic machining of CFRP composites: a study on power consumption
}

W. L. Cong, Z. J. Pei, T. W. Deines, Anil Srivastava, L. Riley, C. Treadwell

\section{How to cite this manuscript}

If you make reference to this version of the manuscript, use the following information:

Cong, W. L., Pei, Z. J., Deines, T. W., Srivastava, A., Riley, L., \& Treadwell, C. (2012). Rotary ultrasonic machining of CFRP composites: A study on power consumption.

Retrieved from http://krex.ksu.edu

\section{Published Version Information}

Citation: Cong, W. L., Pei, Z. J., Deines, T. W., Srivastava, A., Riley, L., \& Treadwell, C. (2012). Rotary ultrasonic machining of CFRP composites: A study on power consumption. Ultrasonics, 52(8), 1030-1037.

Copyright: @ 2012 Elsevier B.V.

Digital Object Identifier (DOI): doi:10.1016/j.ultras.2012.08.007

Publisher's Link:

http://www.sciencedirect.com/science/article/pii/S0041624X12001606

This item was retrieved from the K-State Research Exchange (K-REx), the institutional repository of Kansas State University. K-REx is available at http://krex.ksu.edu 


\title{
Rotary ultrasonic machining of CFRP
}

\section{composites: a study on power consumption}

\author{
W.L. Cong, Z.J. Pei ${ }^{*}$, T.W. Deines, \\ Department of Industrial and Manufacturing Systems Engineering, \\ Kansas State University, \\ Manhattan, KS 66506, USA
}

Anil Srivastava

TechSolve Inc. Cincinnati, Ohio 45237, USA

\author{
L. Riley \\ Department of Electrical and Computer Engineering, \\ Kansas State University, \\ Manhattan, KS 66506, USA

\section{Treadwell} \\ Sonic-Mill, 7500 Bluewater Road NW, \\ Albuquerque, NM 87121, USA
}

\section{Keywords:}

Carbon fiber reinforced plastic composite, Drilling, Grinding, Power consumption, Rotary ultrasonic machining.

\footnotetext{
* Corresponding author. Tel.: +1 785532 3436; fax: +1 7855323738.

E-mail address: zpei@ksu.edu (Z.J. Pei).
} 


\begin{abstract}
Carbon fiber reinforced plastic (CFRP) composites are very difficult to machine. A large number of holes need to be drilled in CFRP for many applications. Therefore, so it is important to develop cost-effective drilling processes. CFRP has been drilled by rotary ultrasonic machining (RUM) successfully. The literature has reports about the effects of input variables on output variables (including cutting force, torque, surface roughness, tool wear, and workpiece delamination) in RUM of CFRP. However, there are no reports on power consumption in RUM of CFRP. This paper reports the first study on power consumption in RUM of CFRP. It reports an experimental investigation on effects of input variables (ultrasonic power, tool rotation speed, feedrate, and type of CFRP) on power consumption of each component (including ultrasonic power supply, spindle motor, coolant pump, and air compressor) and the entire RUM system.
\end{abstract}

\title{
1. Introduction
}

Carbon fiber reinforced plastic (CFRP) composites are increasingly used as primary structural materials in the aerospace industry [Mangalgiri, 1999]. Superior properties of CFRP include low density (lower than aluminum); high strength (as strong as high-strength steels); high stiffness (stiffer than titanium); good toughness; good fatigue, creep, wear, and corrosion resistance; low friction coefficient; good dimensional stability (about zero coefficient of thermal expansion); and high vibration damping ability [Chung DDL 2010; Arul et al. 2006; Sadat et al. 
1995; Davim and Reis 2003; Lambert 1987; Guu et al., 2001; Mallick 1997; Schwartz 1992; Morgan 2005; Park et al. 1995; Ruegg and Habermeier 1981]. Due to some of these superior properties, CFRPs are very difficult to machine. A large number of holes need to be drilled in CFRP for many applications (especially in aircraft assembling) [Boeing Co. Web]. Therefore, it is important to develop cost-effective drilling processes.

CFRP has been drilled by rotary ultrasonic machining (RUM) successfully [Li et al. 2007; Cong et al. 2011abcd, Feng et al. 2011]. RUM is a hybrid machining process that combines material removal mechanisms of diamond grinding and ultrasonic machining. Figure 1 illustrates the RUM process. The cutting tool is a core drill with metal-bonded diamond abrasives. During machining, the rotating tool vibrates axially at an ultrasonic frequency (typically $20 \mathrm{kHz}$ ) and feeds along its axial direction towards the workpiece. Coolant is pumped through the core of the cutting tool, washing away the swarf and preventing the cutting zone from overheating.

The literature contains several studies on RUM of CFRP. Effects of input variables (including ultrasonic power, tool rotation speed, feedrate, and coolant type) on output variables (including cutting force, torque, surface roughness, delamination, and tool wear) have been investigated [Li et al. 2007; Cong et al. 2011abcd, Feng et al. 2011]. Using the same CFRP workpiece material and similar machining conditions, twist drilling and RUM have been compared [Cong et al. 2011d]. Also, to reduce the costs associated with cutting fluids, RUM of 
CFRP using cold air as coolant has been studied [Cong et al. 2011abc]. Feasible regions in RUM of CFRP using cold air as coolant have been identified [Cong et al. 2011b]. A comparison of RUM of CFRP using cold air and cutting fluid has been made [Cong et al. 2011c]. These studies have shown that ultrasonic vibration in RUM can reduce cutting force, torque, cutting temperature, workpiece delamination, and tool wear.

The literature has no reports on power consumption in RUM. This study is the first to investigate power consumption in RUM of CFRP. It reports an experimental investigation on effects of input variables (including ultrasonic power, tool rotation speed, feedrate, and type of CFRP) on power consumption of each component (including ultrasonic power supply, spindle motor, coolant pump, and air compressor) and the entire RUM system. It also provides the percentage of each component's power consumption relative to the entire RUM system's power consumption under each experimental condition. There are four sections in this paper. Following this introduction section, Section 2 describes workpiece material properties, experimental conditions, and measurement procedures. Section 3 presents and discusses experimental results. Finally, conclusions are summarized in Section 4. 


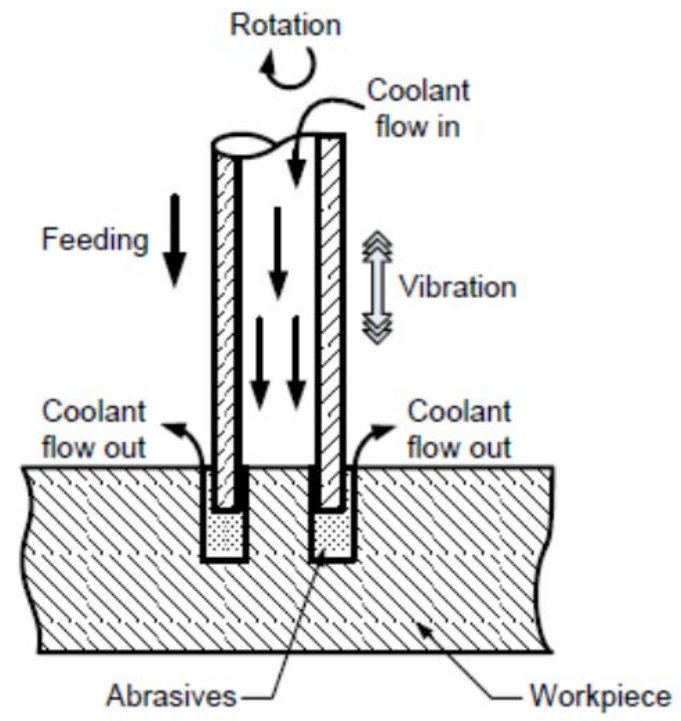

Figure 1 Illustration of rotary ultrasonic machining.

\section{Experimental conditions}

\subsection{Workpiece material properties}

CFRP composites were composed of carbon fibers and epoxy resin. Based on carbon fiber structures, CFRP composites used in this study can be classified into four types: wide yarn woven, thin yarn woven, flake, and unidirectional continuous. Their material properties are listed in Table 1. The fiber structures are illustrated in Figure 2. Specifications of these structures are shown in Table 2. 
Table 1. Workpiece material properties.

\begin{tabular}{lcc}
\hline Property & Unit & Value \\
\hline Density of CFRP & $\mathrm{kg} / \mathrm{m}^{3}$ & 1550 \\
Hardness (Rockwell) & $\mathrm{HRB}$ & $70-75$ \\
Density of epoxy matrix & $\mathrm{kg} / \mathrm{m}^{3}$ & 1200 \\
Elastic modulus of epoxy matrix & $\mathrm{GPa}$ & 4.5 \\
Tensile strength of epoxy matrix & $\mathrm{MPa}$ & 130 \\
Poisson's ratio of epoxy matrix & $/$ & 0.4 \\
Density of carbon fiber & $\mathrm{kg} / \mathrm{m}^{3}$ & 1750 \\
Elastic modulus of carbon fiber & $\mathrm{GPa}$ & 230 \\
Tensile strength of carbon fiber & $\mathrm{GPa}$ & 5 \\
Poisson's ratio of carbon fiber & $/$ & 0.3 \\
\hline
\end{tabular}

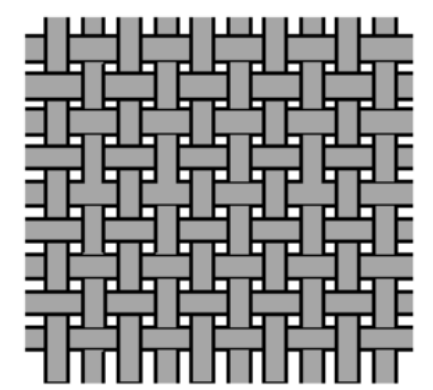

Wide yarn woven (\#1)

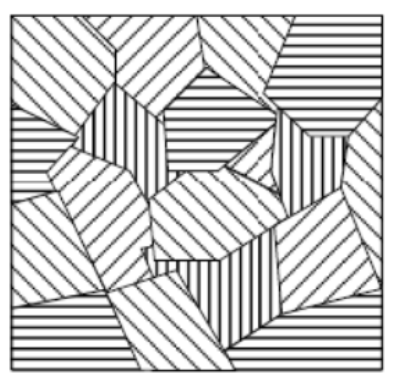

Flake (\#3)

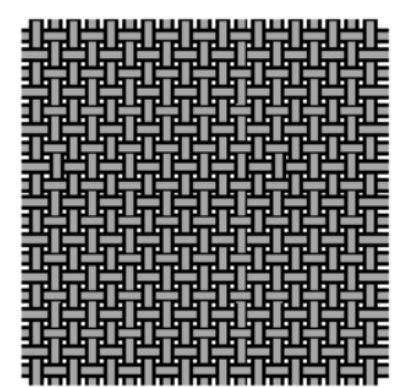

Thin yarn woven (\#2)

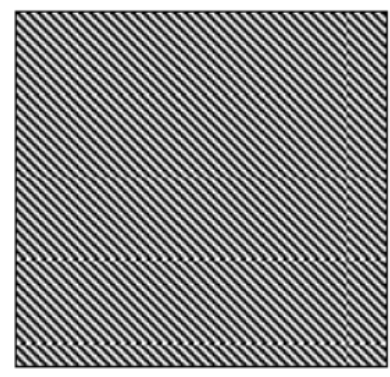

Unidirectional continuous (\#4)

Figure 2 Fiber structures of CFRP.

Table 2 Specifications of carbon fiber structures of different CFRP types.

\begin{tabular}{|c|c|c|c|c|c|}
\hline CFRP & Fiber structure & Orientation & Fiber size & $\begin{array}{c}\text { Number of } \\
\text { Layers }\end{array}$ & Thickness \\
\hline$\# 1$ & Wide yarn woven & $0^{\circ} / 90^{\circ}$ & $\begin{array}{l}2.5 \mathrm{~mm} \text { by } 0.2 \mathrm{~mm} \\
\text { fiber yarn }\end{array}$ & 42 & $16 \mathrm{~mm}$ \\
\hline \#2 & Thin yarn woven & $0^{\circ} / 90^{\circ}$ & $\begin{array}{l}0.35 \mathrm{~mm} \text { by } 0.1 \mathrm{~mm} \\
\text { fiber yarn }\end{array}$ & 20 & $7 \mathrm{~mm}$ \\
\hline \#3 & Flake & N/A & $\begin{array}{l}0.1 \mathrm{~mm} \text { thickness } \\
\text { fiber flake }\end{array}$ & N/A & $12 \mathrm{~mm}$ \\
\hline \#4 & $\begin{array}{l}\text { Unidirectional } \\
\text { continuous }\end{array}$ & $45^{\circ}$ & $0.2 \mathrm{~mm}$ fiber layer & 24 & $18 \mathrm{~mm}$ \\
\hline
\end{tabular}




\subsection{Experimental set-up}

The experiments were performed on a rotary ultrasonic machine (Series 10, Sonic-Mill, Albuquerque, NM, USA). The experimental set-up is schematically illustrated in Figure 3. It mainly consisted of an ultrasonic spindle system, a data acquisition system, and a cooling system. The ultrasonic spindle system was comprised of an ultrasonic spindle, a power supply, and a spindle motor with speed controller. The power supply converted $(60 \mathrm{~Hz})$ electrical supply to high-frequency $(20 \mathrm{kHz})$ electrical energy. This high-frequency electrical energy was provided to a piezoelectric converter (located in the ultrasonic spindle) that changed high-frequency electrical energy into mechanical vibration. The ultrasonic vibration was amplified and transmitted to the cutting tool. This caused the cutting tool to vibrate at the frequency of $20 \mathrm{kHz}$. The amplitude of ultrasonic vibration could be adjusted by changing the setting of output control of the power supply. A motor (SJ-PF, Mitsubishi Electric Crop., Tokyo, Japan) attached atop the ultrasonic spindle supplied the rotational motion of the tool and different speeds were obtained by adjusting the speed controller. The cooling system was comprised of pump, coolant tank, pressure regulator, flow rate and pressure gauges, and valves. The cooling system provided coolant to the spindle and the interface of machining. 


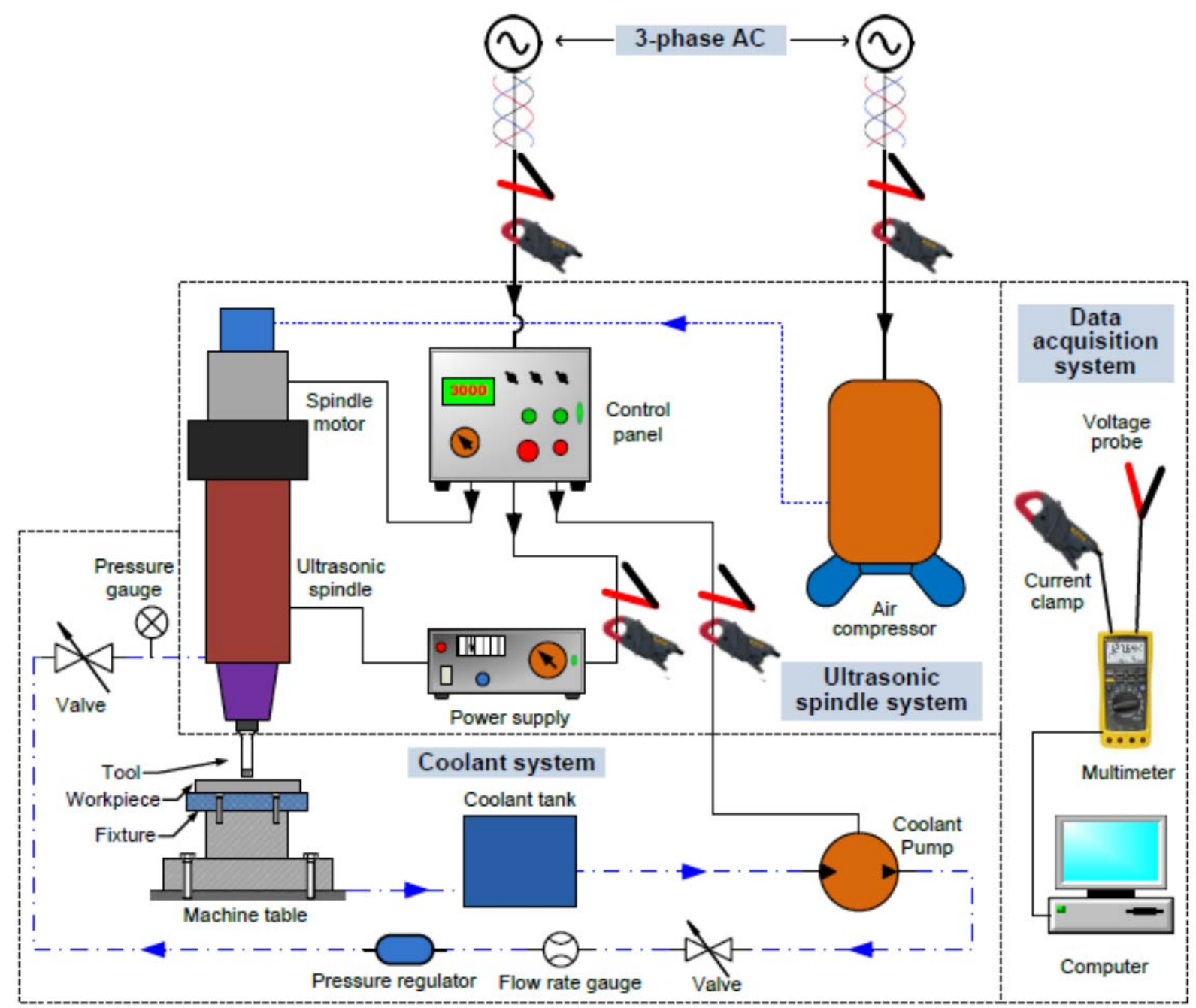

Figure 3 Illustration of experimental set-up.

The up and down movement of the spindle was driven (through a hydraulic cylinder) by highpressure compressive air. The compressive air was provided by a stand-alone air compressor (CI523E80V, North Central Air, Downs, KS, USA). The air compressor started running if the air pressure was below 150 psi. The air compressor would keep running until the air pressure reached 180 psi. The air pressure decreased as each hole was drilled. About 30 holes could be 
drilled within one running cycle of the air compressor. This working cycle of the air compressor is illustrated in Figure 4.

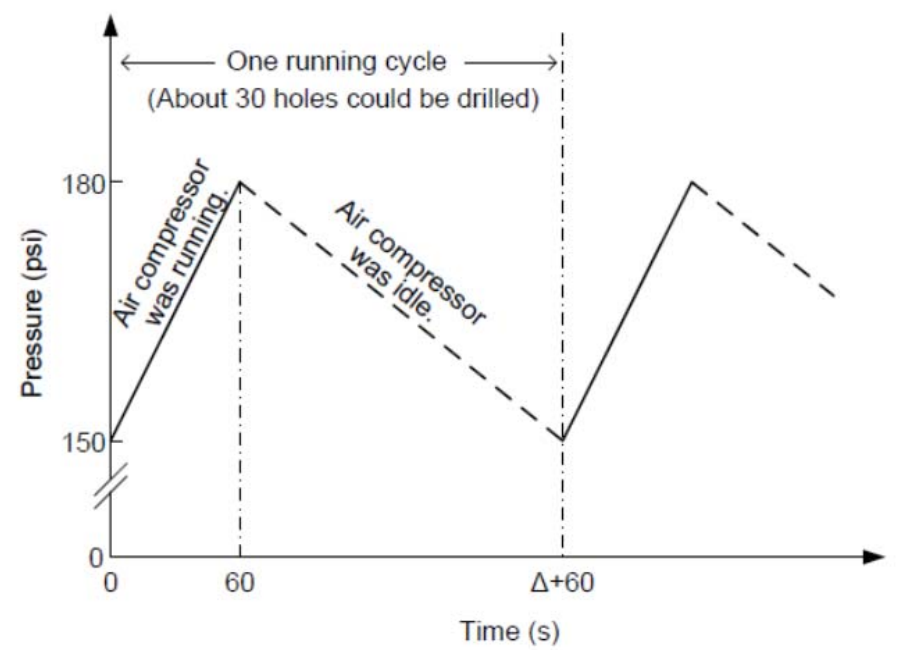

Figure 4 Illustration of the working cycle of the air compressor.

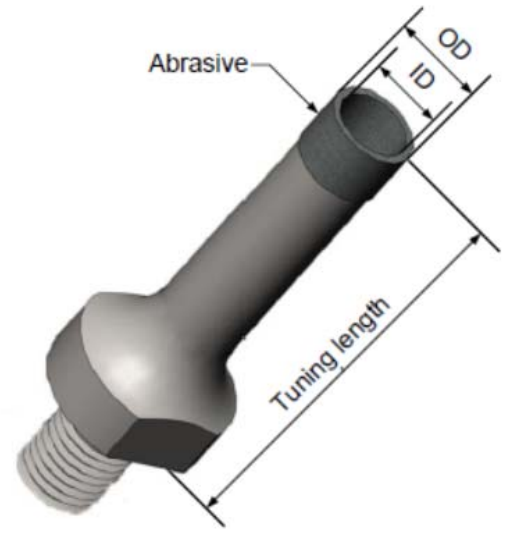

Figure 5 Illustration of a metal-bonded diamond core drill.

Cutting tools used were metal-bonded diamond core drills (NBR Diamond Tool Corp., LaGrangeville, NY, USA), as illustrated in Figure 5. The outer and inner diameters (OD and ID) of the cutting tools were $9.54 \mathrm{~mm}$ and $7.82 \mathrm{~mm}$, respectively, and tuning length was $45 \mathrm{~mm}$. The diamond abrasives had mesh size of $80 / 100$ and concentration of 100 . The metal bond was of B type.

Following input variables were varied in the experiments:

- Types of CFRP: Different CFRP fiber structures.

- Spindle speed: Rotational speed of cutting tool;

- Feedrate: Feedrate of cutting tool;

- Ultrasonic power: Percentage of power from ultrasonic power supply. As illustrated in 
Figure 6, there was an almost linear relationship between ultrasonic power and ultrasonic vibration amplitude and higher ultrasonic power would produce higher ultrasonic vibration amplitude.

The values of these input variables are shown in Table 3. Only one variable was changed at a time while keeping other variables constant. The pressure and flow rate of coolant were kept the same at $40 \mathrm{psi}$ and $1.5 \mathrm{lpm}$, respectively. Four holes were drilled under each machining condition.

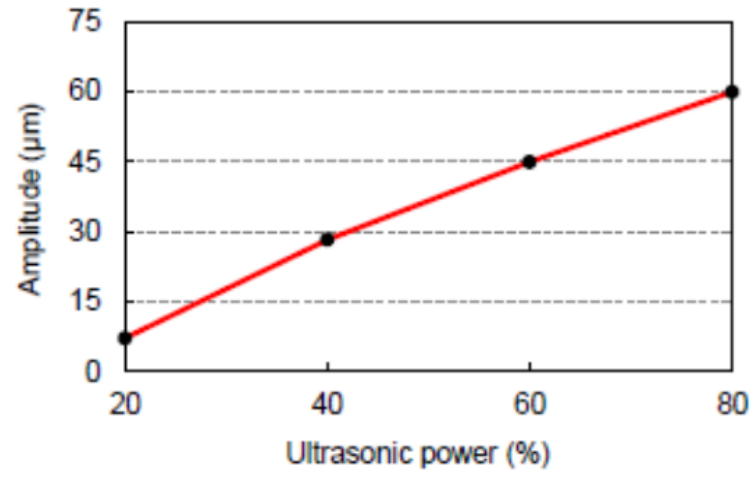

Figure 6 Relationship between ultrasonic power and amplitude.

Table 3. Input variables and their values.

\begin{tabular}{ll}
\hline Variable & \multicolumn{1}{c}{ Value } \\
\hline Ultrasonic power (\%) & $0 ; 20 ; 40 ; 60 ; 80$ \\
Tool rotation speed (rpm) & $1000 ; 2000 ; 3000 ; 4000 ; 5000$ \\
Feedrate (mm/s) & $0.1 ; 0.3 ; 0.5 ; 0.7$ \\
CFRP type & Wide yarn woven; Thin yarn woven; \\
& Flake; Unidirectional continuous \\
\hline
\end{tabular}




\subsection{Measurement procedures}

The power consumption presented in this paper was the electricity energy (W) consumed when drilling a hole in the workpiece material divided by the workpiece thickness (mm). Note that the CFRP workpieces have different thicknesses.

Power consumption of the ultrasonic power supply was calculated by

$$
W_{u}=\frac{U_{u} \cdot I_{u}}{3600 \cdot F}
$$

where $W_{u}$ was the power consumption of ultrasonic power supply $(\mathrm{w} \cdot \mathrm{h} / \mathrm{mm}) ; U_{u}$ was the actual electricity voltage of ultrasonic power supply $(\mathrm{V}) ; I_{u}$ was the measured current of ultrasonic power supply during machining (A); and $F$ was the feedrate $(\mathrm{mm} / \mathrm{s})$.

Power consumption of the coolant pump was calculated by

$$
W_{c}=\frac{U_{c} \cdot I_{c}}{3600 \cdot F}
$$

where $W_{c}$ was the power consumption of coolant pump $(\mathrm{w} \cdot \mathrm{h} / \mathrm{mm}) ; U_{c}$ was the voltage for coolant pump (V); $I_{c}$ was the measured current of coolant pump during machining (A); and $F$ was the feedrate $(\mathrm{mm} / \mathrm{s})$.

Power consumption of the air compressor was calculated by

$$
W_{a}=\frac{U_{a} \cdot I_{a} \cdot t_{a}}{3600 \cdot n \cdot T h}
$$


where $W_{a}$ was the power consumption of air compressor $(\mathrm{w} \cdot \mathrm{h} / \mathrm{mm}) ; U_{a}$ was the actual electricity voltage of air compressor $(\mathrm{V}) ; I_{a}$ was the measured current of air compressor when it was running (A); $t_{a}$ was the period of time during which the air compressor was running (s); $n$ was the number of holes that could be drilled within one air compressor activation cycle; and Th was the thickness of the workpiece (mm).

Because of the machine design, it is difficult to measure voltage and current of the spindle motor directly. Power consumption of the spindle motor was calculated by

$$
W_{s}=W_{p}-W_{u}-W_{c}=\frac{U_{p} \cdot I_{p}}{3600 \cdot F}-W_{u}-W_{c}
$$

where $W_{s}$ was the power consumption of spindle motor $(\mathrm{w} \cdot \mathrm{h} / \mathrm{mm}) ; W_{p}$ was power consumption of the control panel (w.h/mm); $U_{p}$ was the measured electricity voltage of control panel (V); $I_{p}$ was the measured current of the control panel during machining (A); and $F$ was the feedrate $(\mathrm{mm} / \mathrm{s})$.

Power consumption of the entire RUM system was

$$
W_{\mathrm{RUM}}=W_{a}+W_{p}
$$

The current and voltage of ultrasonic power supply, coolant pump, air compressor, and control panel (including spindle motor, ultrasonic power supply, and coolant pump) were measured by a data acquisition system. It was consisted of a current clamp, a voltage probe, a multimeter 
(Model 189, Fluke Crop., Everett, WA), and a computer with Flukeview Forms software (Version 3.4, Fluke Crop., Everett, WA). The sampling rate was set at $1 \mathrm{~Hz}$.

\section{Results and discussion}

\subsection{Effects of ultrasonic power}

Effects of ultrasonic power on power consumption for the entire RUM system and each component are shown in Figure 7. When ultrasonic power increased from 0 to $80 \%$, power consumption of ultrasonic power supply increased slightly, power consumption of spindle motor decreased significantly, power consumption of coolant pump and air compressor kept constant, power consumption of the entire RUM system almost kept constant. 


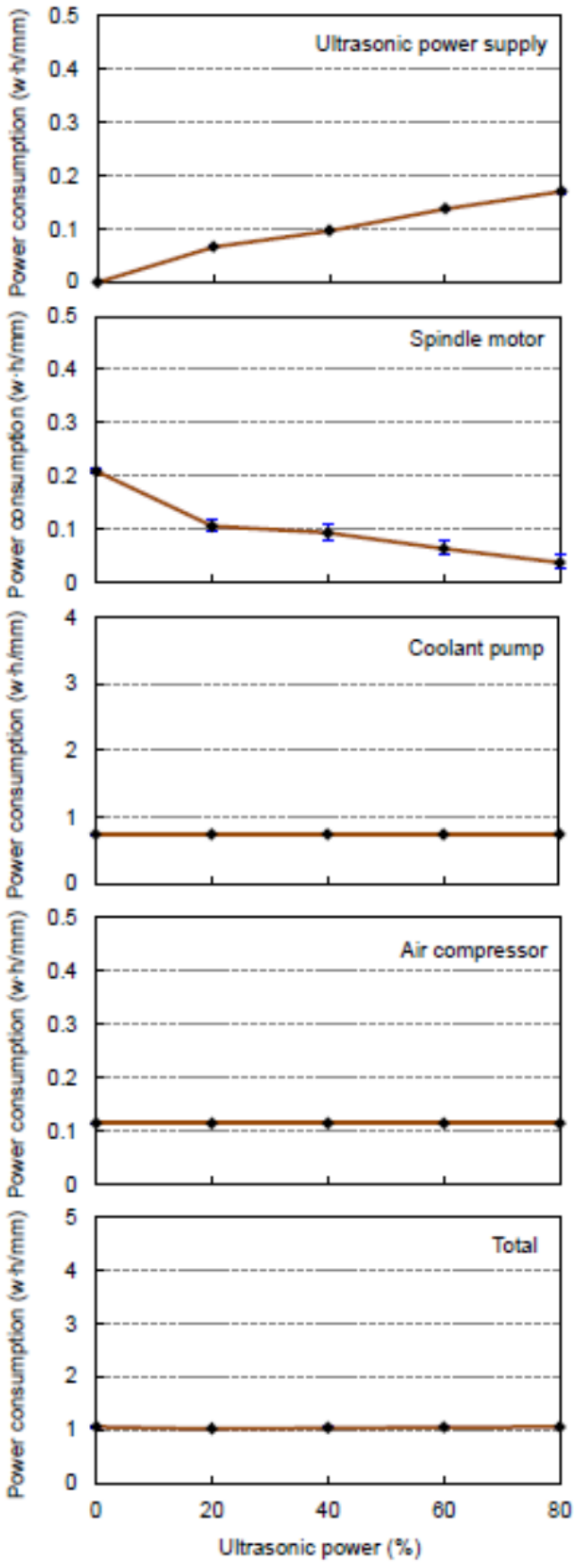

Figure 7 Effects of ultrasonic power.

(Tool rotation speed $=3000 \mathrm{rpm}$; Feedrate $=0.5 \mathrm{~mm} / \mathrm{s} ;$ CFRP \#1) 


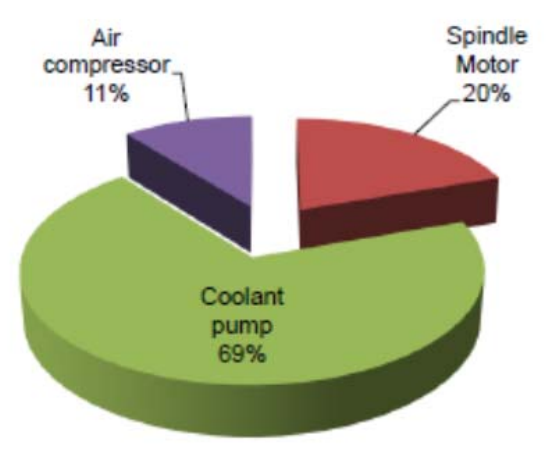

(a) Ultrasonic power $=0 \%$

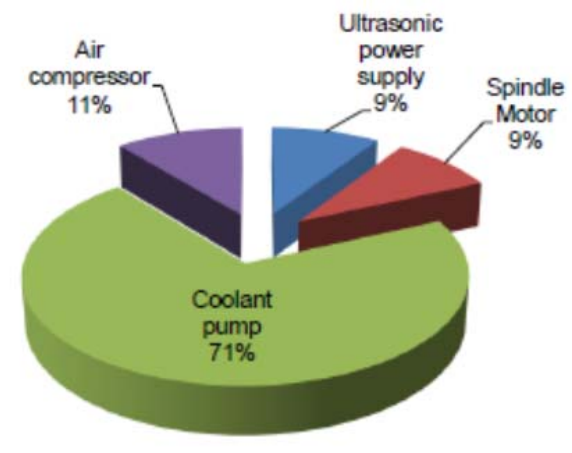

(b) Ultrasonic power $=40 \%$

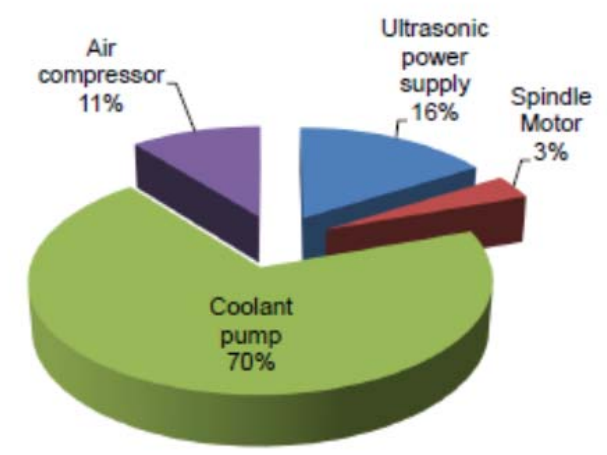

(c) Ultrasonic power $=80 \%$

Figure 8 Power consumption percentage of each component under different settings of ultrasonic power.

(Tool rotation speed $=3000 \mathrm{rpm} ;$ Feedrate $=0.5 \mathrm{~mm} / \mathrm{s} ;$ CFRP \#1)

Power consumption percentages of each component under different settings of ultrasonic power are shown in Figure 8. For different settings of ultrasonic power, power consumption of coolant pump always had the highest percentage (about 70\% of the entire RUM system power consumption), and power consumption percentage of air compressor kept unchanged at $11 \%$. As the ultrasonic power increased, power consumption percentage of ultrasonic power supply increased from 0 to $16 \%$, in contrast, spindle motor power consumption percentage decreased from $20 \%$ to $3 \%$.

Effects of ultrasonic power on other output variables (including cutting force, torque, and surface 
roughness) had been studied [Cong et al., 2011c]. When ultrasonic power increased from $0 \%$ to $80 \%$, cutting force and torque decreased. The decrease of cutting force and torque were about $20 \%$ and $40 \%$, respectively. When ultrasonic power increased from 0 to $80 \%$, surface roughness decreased first and then increased. Compared with RUM without ultrasonic power, the decrease of surface roughness was about $10 \%$. It is noted that ultrasonic power in RUM can reduce cutting force, torque, and surface roughness, without increasing power consumption. 


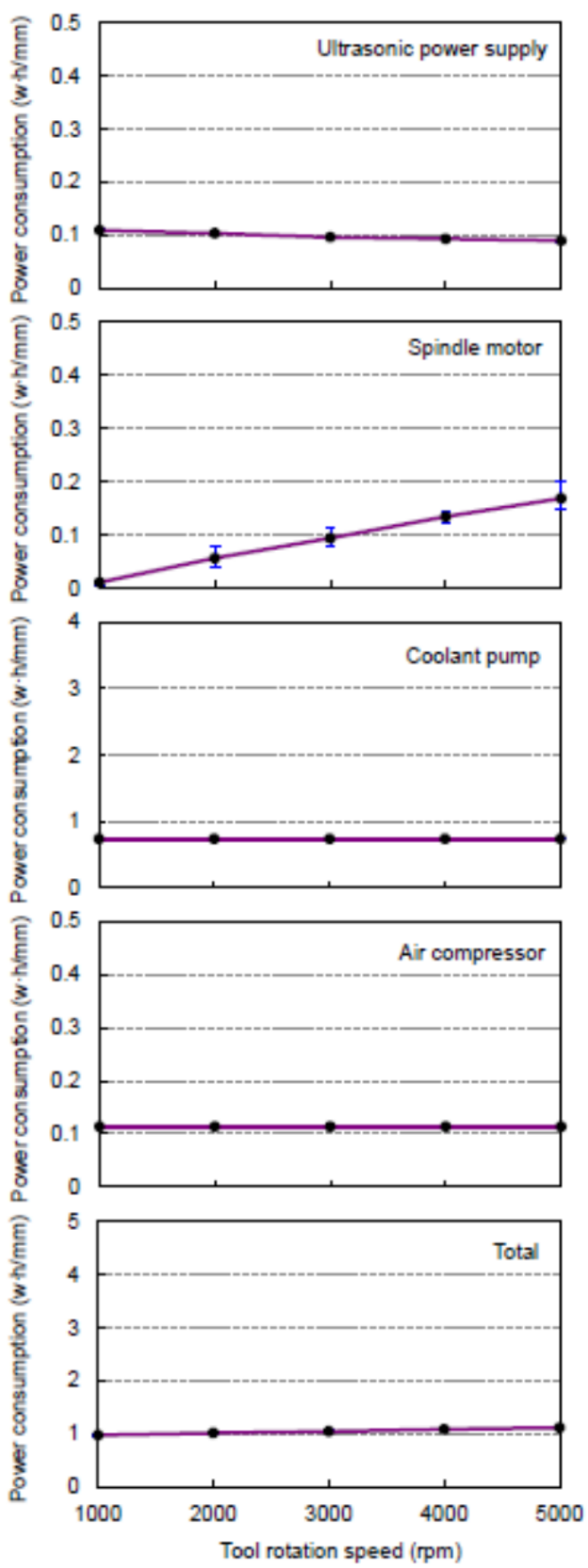

Figure 9 Effects of tool rotation speed.

(Ultrasonic power $=30 \%$; Feedrate $=0.5 \mathrm{~mm} / \mathrm{s} ; \mathrm{CFRP} \# 1$ )

\subsection{Effects of tool rotation speed}

Effects of tool rotation speed on power consumption are shown in Figure 9. As tool rotation 
speed increased, power consumption of ultrasonic power supply decreased, power consumption of spindle motor increased dramatically, power consumption of coolant pump and air compressor kept unchanged, and power consumption of the entire RUM system increased slightly.

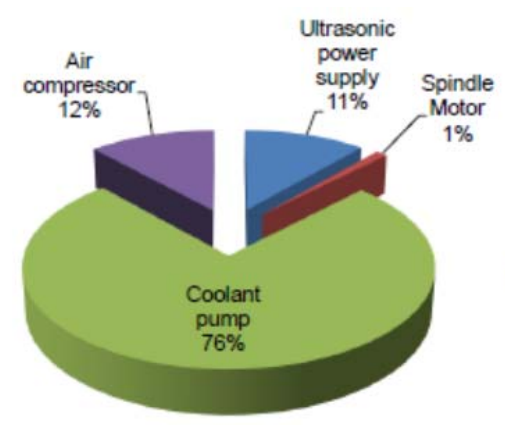

(a) Tool rotation speed $=1000 \mathrm{rpm}$

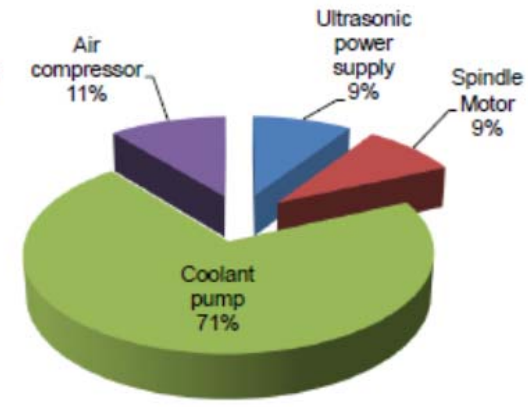

(b) Tool rotation speed $=3000 \mathrm{rpm}$

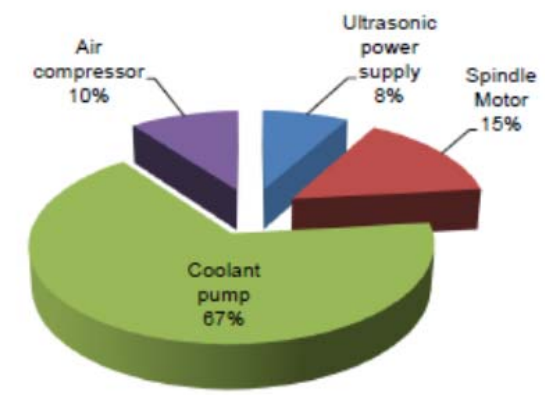

(c) Tool rotation speed $=5000 \mathrm{rpm}$

Figure 10 Power consumption percentage of each component under different settings of tool rotation speed.

(Ultrasonic power $=30 \%$; Feedrate $=0.5 \mathrm{~mm} / \mathrm{s} ;$ CFRP \#1)

Power consumption percentages of each component under different settings of tool rotation speed are shown in Figure 10. For different settings of tool rotation speed, power consumption of coolant pump always had the largest percentage. As tool rotation speed increased from 1000 to 5000 rpm, power consumption percentage of ultrasonic power supply decreased slightly from $11 \%$ to $8 \%$, power consumption percentage of spindle motor increased from $1 \%$ to $15 \%$, power consumption percentage of coolant pump decreased from $76 \%$ to $67 \%$, and power consumption percentage of air compressor decreased slightly from $12 \%$ to $10 \%$. 


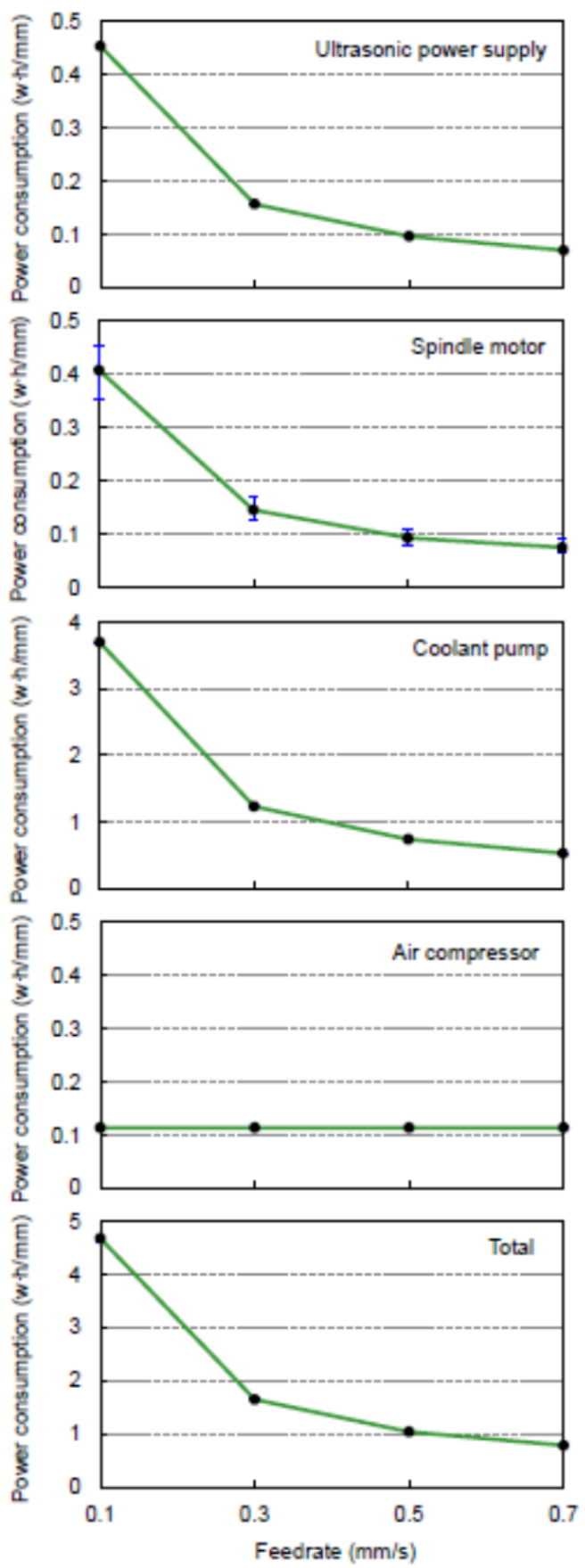

Figure 11 Effects of feedrate.

(Ultrasonic power $=30 \%$; Tool rotation speed $=3000 \mathrm{rpm}$; CFRP \#1)

\subsection{Effects of feedrate}

Effects of feedrate on power consumption are shown in Figure 11. As feedrate increased, power 
consumptions of ultrasonic power supply, spindle motor, and coolant pump decreased dramatically, power consumption of air compressor kept the same, and power consumption of the entire RUM system increased remarkably.

Power consumption percentages of each component under different settings of feedrate are shown in Figure 12. As feedrate increased from 0.1 to $0.7 \mathrm{~mm} / \mathrm{s}$, power consumption percentage of air compressor increased from $2 \%$ to $14 \%$, power consumption percentage of coolant pump decreased from $79 \%$ to $67 \%$, and power consumption percentages of ultrasonic power supply and spindle motor did not change much and remained as approximately $9 \%$.

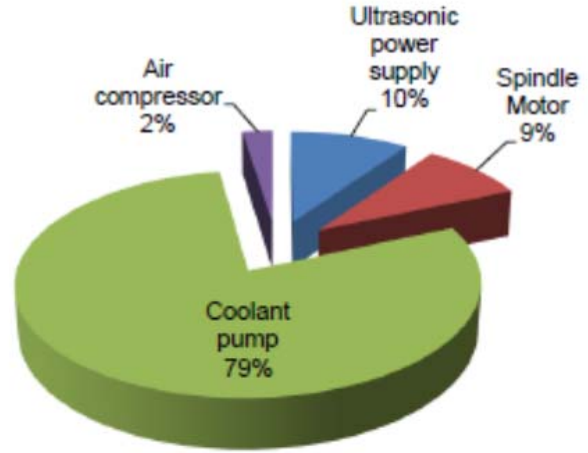

(a) Feedrate $=0.1 \mathrm{~mm} / \mathrm{s}$

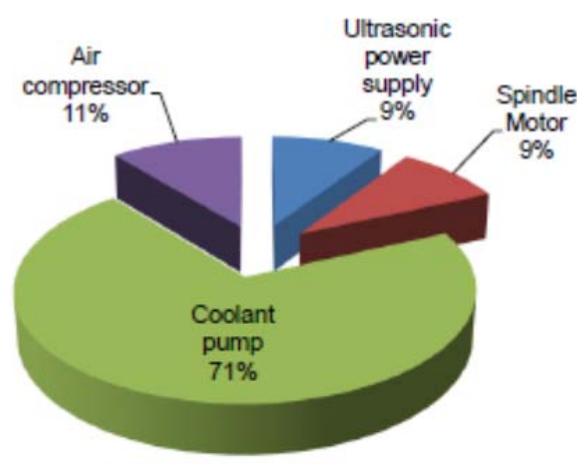

(c) Feedrate $=0.5 \mathrm{~mm} / \mathrm{s}$

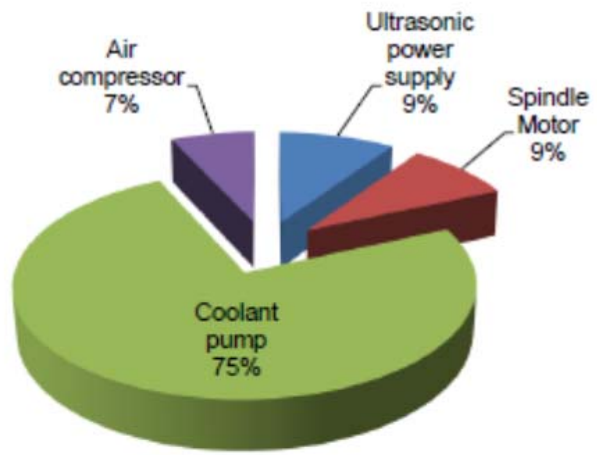

(b) Feedrate $=0.3 \mathrm{~mm} / \mathrm{s}$

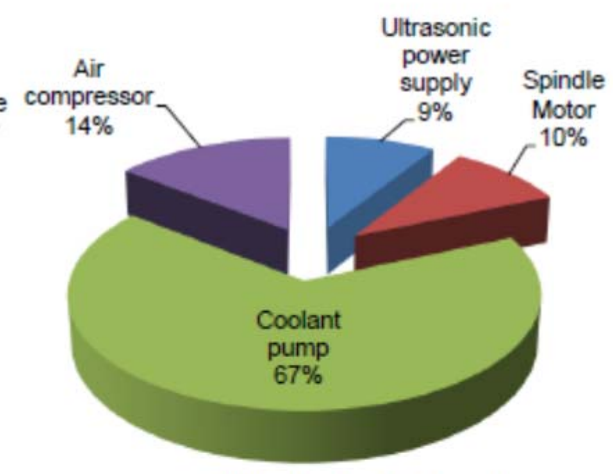

(d) Feedrate $=0.7 \mathrm{~mm} / \mathrm{s}$

Figure 12 Power consumption percentage of each component under different settings of feedrate. (Ultrasonic power $=30 \%$; Tool rotation speed $=3000 \mathrm{rpm}$; CFRP \#1) 


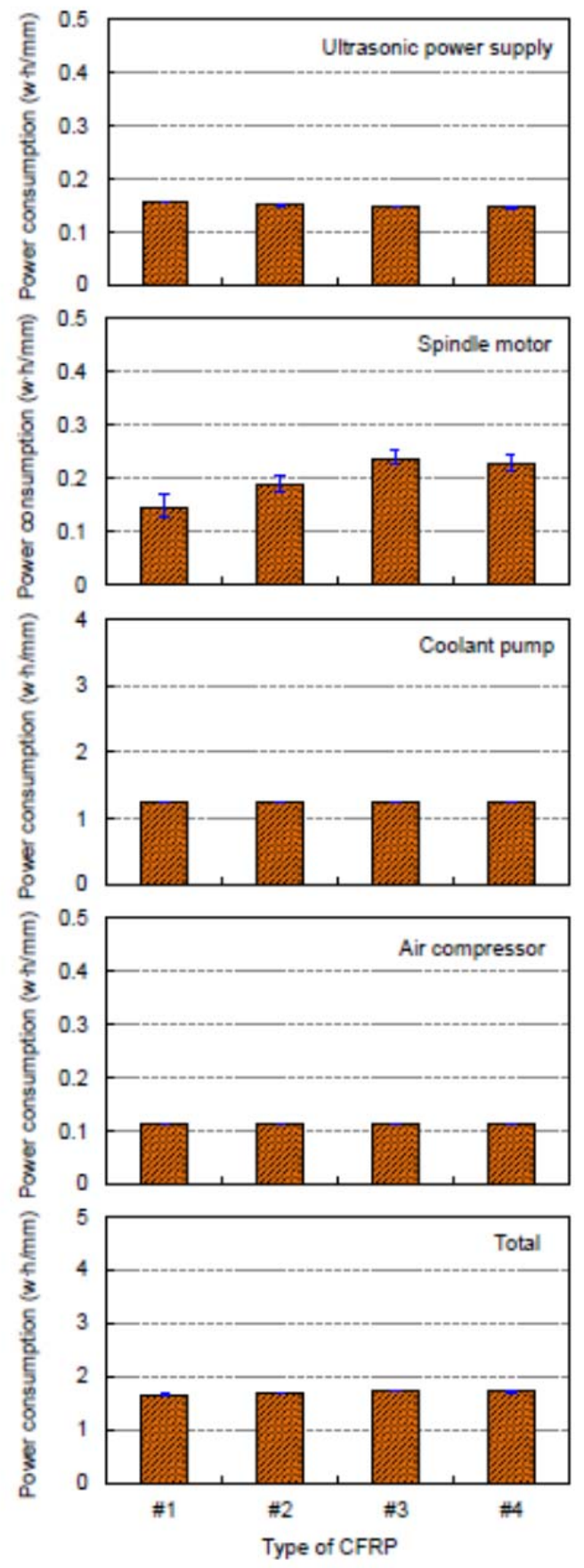

Figure 13 Effects of CFRP type.

(Ultrasonic power $=30 \%$; Tool rotation speed $=3000 \mathrm{rpm}$; Feedrate $=0.3 \mathrm{~mm} / \mathrm{s}$ )

\subsection{Effects of CFRP type}

Effects of CFRP type on power consumption are shown in Figure 13. CFRP type significantly 
affected power consumption of ultrasonic power supply and spindle motor. The power consumption of ultrasonic power supply was the highest when machining CFRP \#1 (with wide yarn woven fiber structure) and the lowest when machining CFRP \#3 (with flake fiber structure). In contrast, power consumption of spindle motor was the highest when machining CFRP \#3 and the lowest when machining CFRP \#1. For different types of CFRP, power consumption of coolant pump and air compressor kept unchanged. Power consumption of the entire RUM system did no change much for these different CFRP types.

Power consumption percentages of each component for RUM of different CFRP types are shown in Figure 14. When CFRP type changed, power consumption of coolant pump always had the highest percentage $(71 \% \sim 73 \%)$. Power consumption percentage of air compressor stayed at 7\%. Power consumption percentages of ultrasonic power supply and spindle motor changed slightly. 


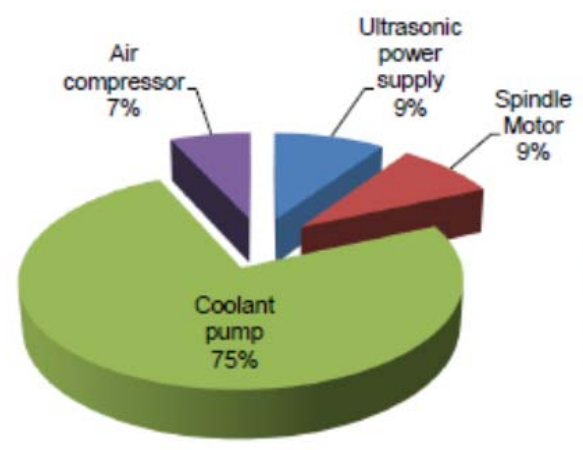

(a) CFRP \#1

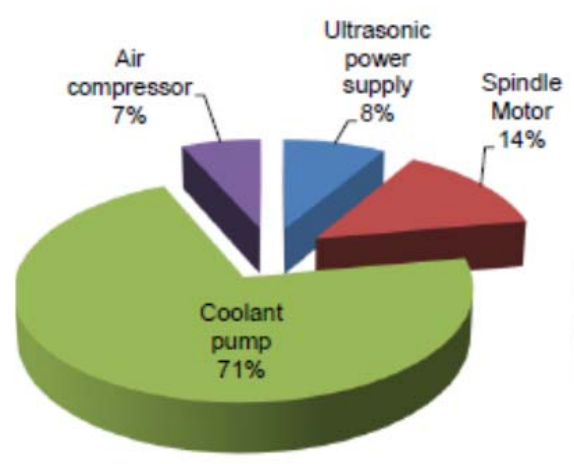

(c) CFRP \#3

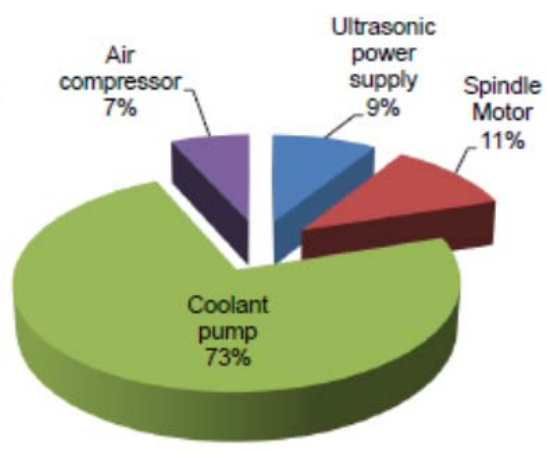

(b) CFRP \#2

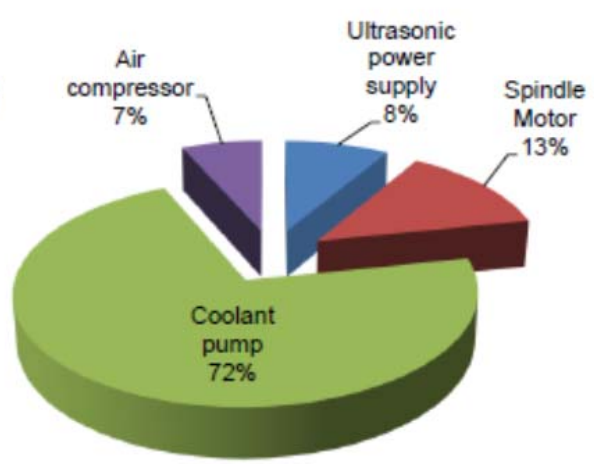

(d) CFRP \#4

Figure 14 Power consumption percentage of each component under different CFRP type.

(Ultrasonic power $=30 \%$; Tool rotation speed $=3000 \mathrm{rpm} ;$ Feedrate $=0.3 \mathrm{~mm} / \mathrm{s}$ )

\section{Conclusions}

This paper reported a study on power consumption in RUM of CFRP. Power consumption of the entire RUM system and each component under different settings of ultrasonic power, tool rotation speed, feedrate, and CFRP type was studied. The following conclusions are drawn from this study:

(1) As ultrasonic power increased or tool rotation speed decreased, power consumption of ultrasonic power supply increased slightly, power consumption of spindle motor decreased 
dramatically, power consumption of coolant pump and air compressor kept unchanged, and power consumption of the entire RUM system increased slightly. As feedrate decreased, power consumptions of ultrasonic power supply, spindle motor, and coolant pump decreased dramatically, power consumption of air compressor kept the same, and power consumption of the entire RUM system increased remarkably.

(2) CFRP type significantly affected power consumption of ultrasonic power supply and spindle motor. For different CFRP types, power consumption of coolant pump and air compressor kept unchanged. Power consumption of the entire RUM system did no change much for these different CFRP types.

(3) As the ultrasonic power increased or tool rotation speed, power consumption percentage of ultrasonic power supply increased. In contrast, power consumption percentage of spindle motor decreased, power consumption percentage of air compressor kept unchanged.

(4) Under all the test conditions, power consumption of coolant pump always had the highest percentage (higher than $65 \%$ of the entire RUM system power consumption).

(5) As ultrasonic power increased or tool rotation speed decreased, power consumption percentage of ultrasonic power supply increased, power consumption percentage of spindle motor decreased.

(6) As feedrate increased, power consumption percentage of air compressor increased, power consumption percentage of coolant pump decreased, and power consumption percentages of ultrasonic power supply and spindle motor did not change much. 
(7) For different CFRP types, the percentage of each component did not change much.

\section{Acknowledgements}

The work was supported by the National Science Foundation through award CMMI-0900462.

The authors gratefully extend their acknowledgements to N.B.R. Diamond Tool Corp. for supplying the diamond core drills.

\section{References}

[1] Arul S., Vijayaraghavan L., Malhotra S.K., and Krishnamurthy R., (2006), The effect of vibratory drilling on hole quality in polymeric composites, International Journal of Machine Tools and Manufacture, 46(3-4), pp. 252-259.

[2] Boeing Co. web, (2011), 787 Dreamliner Program Fact Sheet, available at: http://www.boeing.com/commercial/787family/programfacts.html, accessed in Nov 20.

[3] Chung D.D.L., (2010), Composite materials science and applications, 2nd ed. SpringerVerlag, London, UK.

[4] Cong W.L., Feng Q., Deines T., Pei Z.J., and Treadwell C., (2011a), Dry machining of carbon fiber reinforced plastic composite by rotary ultrasonic machining: effects of machining variables. Proceedings of the ASME 2011 International Manufacturing Science and Engineering Conference, Corvallis, OR, USA.

[5] Cong W.L., Feng Q., Deines T., Pei Z.J., and Treadwell C., (2011b), Rotary ultrasonic 
machining of CFRP using cold air as coolant: feasible regions, Journal of Reinforced Plastics and Composites, 30(10), pp. 899-906, (DOI: 10.1177/0731684411416266).

[6] Cong, W.L., Feng, Q., Pei, Z.J., Deines, T.W., and Treadwell, C., (2011c), Rotary ultrasonic machining of carbon fiber reinforced plastic composites: using cutting fluid versus cold air as coolant, Journal of Composite Materials, (DOI: 10.1177/0021998311424625).

[7] Cong, W.L., Pei, Z.J., Feng, Q., Deines, T.W., and Treadwell, C., (2011d), Rotary ultrasonic machining of CFRP: a comparison with twist drilling, accepted to appear in Journal of Reinforced Plastics and Composite.

[8] Davim J.P. and Reis P., (2003), Drilling carbon fiber reinforced plastics manufactured by autoclave-experimental and statistical study, Mater Design, 24(5), pp. 315-324.

[9] Feng, Q., Cong, W.L., Pei, Z.J., and Ren, C.Z., (2011), Rotary ultrasonic machining of carbon fiber reinforced polymer: feasibility study, accepted to appear in Machining Science and Technology.

[10]Guu Y.H., Hocheng H., Tai N.H., and Liu S.Y., (2001), Effect of electrical discharge machining on the characteristics of carbon fiber reinforced carbon composites, Journal of Materials Science, 36(8), pp. 2037-2043.

[11]Lambert B.K., (1987), Cutting and drilling of composite materials, Carbide Tool Journal, 19, pp. 31-34.

[12]Li Z.C., Pei Z.J., Sisco T., Micale A.C., and Treadwell C., (2007), Experimental study on rotary ultrasonic machining of graphite/epoxy panel. Proceedings of the ASPE 2007 Spring 
Topical Meeting on Vibration Assisted Machining Technology, Chapel Hill, NC, USA, pp. $52-57$.

[13]Mallick P.K., (1997), Composite Engineering Handbook, Marcel Dekker Inc., New York, NY, USA.

[14]Mangalgiri P.D., (1999), Composite materials for aerospace applications, Bulletin of Materials Science, 22(3), pp. 657-664.

[15] Morgan P., (2005), Carbon fibers and their composites, CRC Press, Taylor \& Francis Group, Boca Raton, FL, USA.

[16]Park K.Y., Choi J.H., and Lee D.G., (1995), Delamination-free and high efficiency drilling of carbon fiber reinforced plastics, Journal of Composite Materials, 29(15), pp. 1988-2002.

[17]Ruegg C.H. and Habermeier J., (1981), Composite propeller shafts: design and optimization, Automot Eng-UK, 6, pp. 13-15.

[18]Sadat A.B., (1995), Delamination and other types of damage of graphite/epoxy composite caused by machining, Machining of Advanced Materials - Presented at ASME Summer Meeting at University of California, Vol. 208, Los Angeles, AMD, MD-Vol. 59, pp. 41-52.

[19]Schwartz M.M., (1992), Composite materials handbook, 2nd ed. Columbus, McGraw-Hill, OH, USA.

[20]Tangaev I.A., 1975, Power consumption of roller-bit drilling as an index of the miningrelated properties of the solid rock, Soviet Mining Science, 11(1), pp. 74-77. 